\title{
Movie 2: World Allergy: The Disease of Civilization
}

On the occasion of the International Congress of Allergology and Clinical Immunology (ICACI; now called World Allergy Congress) in Stockholm in June 1994, the incoming president, Prof. Alain de Weck, initiated the production of a movie on essential aspects of the history of allergy. The film [see www.karger.com/chial100_movie2] starts with a reflection on history and the presumed first allergic individual, namely Pharaoh Menes from the old dynasty in Egypt, who supposedly died because he was stung by a wasp. However, critical analysis offers an alternative account - that he was killed by a hippopotamus. The movie takes us to the zoo in Monaco and we also learn about the birth of the term anaphylaxis.

Going back in history, the classical questions of Hippocrates about how the patient feels and how to analyze his or her history were for the first time supplemented with regard to allergological questions by Ramazzini, around 1700, who also added a new question regarding the occupation of the patient, thus giving the first description of baker's asthma.
Alain de Weck acts as a guide and interpreter in this movie and gives his often very personal and precisely put thoughts. In a random series of interviews you can see and listen to top researchers, all of whom are regarded as pioneers. Jack Pepys describes the discovery of Micropolyspora as the trigger of farmer's lung, seen as 'the needle in a haystack'. The Nobel laureate Bengt Samuelsson describes his discovery of leukotrienes as carriers of the slow-reacting substance of anaphylaxis. Other Nobel laureates to be mentioned in allergy history are Charles Richet, the discoverer of anaphylaxis, Paul Ehrlich, who came up with the first chemotherapeutic agent and with the side-chain theory that gave an impression on $\mathrm{T}$ cell receptors, and Daniel Bovet, who invented the first antihistamine.

Other pioneers giving interviews in the movie include Larry Lichtenstein on the topic of basophils and their releasability, and S.G.O. Johansson, who reflects on the summer of 1965, when he recognized an abnormal electrophoresis pattern in a single patient which turned out to be the first case of IgE myeloma. Terumasa Miyamoto was the first to provide arosty 
evidence for the role of pollutants in the rising prevalence of allergic diseases, mainly diesel exhaust and cedar pollinosis in Japan. Patrick Holt speculates on the neonatal phase, which is decisive in early life with regard to the development of allergy or tolerance. François Michel stresses the role of allergy in asthma. Bengt Björksten and M. Riikjärf talk about their experience in comparing allergy prevalences between Swedish and Estonian children, and their different lifestyles. Heidrun Behrendt comments on the
German comparison study between West and East German children after reunification and the influence of an 'experimentum dictaturae' upon allergy development, as well as the influence of air pollutants on pollen grains in the ambient air.

Finally, Alain de Weck concludes with the question of whether allergy may be the price to be paid for civilization?

Johannes Ring, Munich 